\title{
Needs of family members of critically ill patients: A comparison of nurses and family perceptions
}

\author{
Mohammad M. Al Barraj ${ }^{1}$, Mirna Fawaz², Lina Kurdahi Badr*3 \\ ${ }^{1}$ American University of Beirut Medical Center, United States \\ ${ }^{2}$ Nursing Department, Faculty of Health Sciences, Beirut Arab University, Beirut, Lebanon \\ ${ }^{3}$ Azusa Pacific University, United States
}

Received: February 25, 2019

Accepted: May 28, 2019

Online Published: June 18, 2019

DOI: $10.5430 /$ jnep.v9n9p81

URL: https://doi.org/10.5430/jnep.v9n9p81

\begin{abstract}
Background and objective: Having a family member admitted to Intensive Care Unit (ICU) is stressful and confusing for family members. The aim of this study was to assess the perception of family members and nurses of their needs and whether those needs are met in four ICUs in Lebanon.

Methods: A descriptive cross-sectional design using the Arabic version of Critical Care Family Need Inventory (CCFNI) and the Needs Met Inventory (NMI) were utilized to investigate the needs of 50 family members of patients and 50 nurses.

Results: Seventeen of 30 need items on the CCFNI were significantly different between family members and nurses mostly related to 'Information' and 'Assurance'. Family members also varied significantly on 5 out of 30 items on the NMI mostly related to 'Support'. There were significant differences in needs between family members in terms of gender, age, and education, and significant differences in perceived needs based on the gender, years of experience, and age of nurses.

Conclusions: The findings provide insight for nurses to consider the different needs of families, the effect of socio-demographic variations when providing care, and to be attuned to the needs of family members for understandable information and assurance of the wellbeing of patients in ICUs.
\end{abstract}

Key Words: Family needs, ICU, Nursing care

\section{INTRODUCTION}

Family members of patients in the ICU often experience stress, powerlessness, and confusion, especially since the majority of the admissions are unexpected and patients are unable to communicate their needs themselves. ${ }^{[1,2]}$ Research has documented that families of patients in the ICU have particular needs as they are confronted with a highly technical and overwhelming environment while they await the outcome of their loved one. ${ }^{[3,4]}$ Therefore, assessing family needs and how they may differ between cultures is necessary to assure quality care.
Several studies in different cultures in the past four decades have documented that although families may be satisfied with care in general, often their needs are not met and there is room for improvement, especially in areas of communication and emotional support. ${ }^{[2,3,5,6,9]}$ Unmet needs of families may be due to the lack of congruency between what health professionals deem important and what families regard as important. ${ }^{[10]}$ In addition, while some family needs may be similar across cultures, others may be unique to a certain population which nurses must become acquainted with in order to provide appropriate care. For example, a study in

*Correspondence: Lina Kurdahi Badr; Email: 1badr@apu.edu; Address: Azusa Pacific University, United States. 
Jordan reported that patients in critical care units recognized physical and technical behaviors by staff as the most crucial caring behaviors, whereas nurses identified teaching behaviors as most essential caring practices. ${ }^{[8]}$ A study in India found that nurses and families of children in a pediatric intensive care unit were different on $13(28 \%)$ out of the 47 perceived needs based on the Critical Care Family Needs Inventory (CCFNI). ${ }^{[11]}$ In the Middle East, family size is generally large and characterized by strong ties among its members who visit the patient, overcrowd the waiting rooms, and want to be involved in the care of the sick patient in the ICU. ${ }^{[3,12]}$ Two recent reviews of the literature in the concluded that in general the needs of patients' family members were unmet and that that not all unmet needs are consistent across cultures. ${ }^{[13,14]}$

Founded on the above, the aim of this study was to compare the perception of critical care nurses versus family members of their most important needs and to assess whether these needs are met or not during a family member's stay in an ICU in Lebanon. Based on previous studies, ${ }^{[5,15,16]}$ we also assessed socio-demographic variables which included: gender, age, education, relationship to patient, and how many days the patient was in the ICU (for family members) and for nurses it included years they had practiced nursing.

\section{Research questions}

(1) What are the significant differences, if any, between how critical care nurses compared to family members perceive their needs during a family member's critical illness?

(2) What are the significant differences, if any, between how critical care nurses and family members perceive if their needs are being met or not during a family member's critical illness?

(3) What are the significant relationships, if any, between the demographic characteristics of nurses and families and their perceptions of needs during a family member's critical illness?

\section{Methods}

\subsection{Design}

A cross-sectional prospective descriptive research design was used which took place between November 2017 and May 2018.

\subsection{Setting}

The study was conducted in four adult Intensive Care Units (ICUs) at a University Medical Center in Lebanon, a 420bed tertiary care center providing inpatient and outpatient services to people in Lebanon and the Middle East. The four critical care units where data was collected have 28 beds and 92 registered nurses. The ratio of nurses to patients is 1 to 1 or 1 to 2 depending on patient acuity. The ICUs included: the Coronary Care Unit (CCU), the Intensive Care Unit (ICU), the Respiratory Care Unit (RCU), and the Neuro Intensive Care Unit (NICU). The ICUs exercise a non-restricted visiting hour policy based on the American College of Critical Care Medicine Task Force practice guidelines, ${ }^{[17]}$ although family members are not allowed to participate in the patient's care or be present during invasive procedures. In these ICUs, the doctor is the "official" spokesperson proving most medical information to patients and their families.

\subsection{Subjects}

Participants for this study included nurses and family members.

Nurses: A convenient sample of all 92 nurses who worked in the ICUs for at least 6 months were sent an online survey with an introductory email with a link to the consent to participate. A reminder email was sent every week after the initial request, for a total of three times. After 12 weeks, 50 nurses had replied and the survey was closed.

Family members: The investigator approached family members to seek their interest in participating. At most, two family members of each patient were surveyed until 50 family members completed the survey. Nurses in each unit were consulted for the eligibility of families, which included the following criteria: they had a family member in a critical care unit for more than 24 hours and were first- or second-degree family members. A first-degree relative is defined as parents, siblings, or children, while a second-degree relative is defined as grandparents, grandchildren, aunts, uncles, nephews, and nieces. They must have visited their family member at least two times during his/her admission. The 24-hour limit was chosen so that only families who had been exposed to the ICU environment and had interacted with the ICU staff were included.

\subsection{Instruments}

Two instruments were used to collect data: The 30-item version of Critical Care Family Needs Inventory/Needs Met Inventory ${ }^{[18]}$ and socio-demographic variables of nurses and relatives.

The abbreviated 30 items CCNFI/NMI was used ${ }^{[19]}$ to assess the self-reported needs of family members and nurses in the critical care units. The Arabic tool adopted from a previous study by Omari, ${ }^{[20]}$ for family members who preferred the Arabic version, was available. Nurses used the English version since they all speak English. The Inventory is divided into two sections: the Critical Care Family Needs 
Inventory (CCFNI) and Needs Met Inventory (NMI). The CCFNI is the most commonly used tool ${ }^{[18]}$ to assess the perceptions of patients' family members and nurses about the importance of various family needs. It has been translated to several languages and includes five domains: Support, Comfort, Assurance, Information, and Proximity. The inventory also includes the Needs Met Inventory (NMI) which assesses whether families perceive that their needs are met or not. While the CCFNI has been used extensively in studies in different cultures, the NMI has been sparingly used. On the CCFNI, responses are scored on a Likert scale of 1 to 4 with 1 indicating not important, 2 = slightly important, 3 $=$ important, and $4=$ very important. The NMI scale uses the same need items as the CCFNI for both family members and nurses and asks how the needs were being met on a four point Likert scale as follows: never met $=1$, sometimes met $=2$, usually met $=3$, always met $=4$. The CCFNI/NMI has established internal reliability ranging from 0.85 to 0.98 and established content validity. ${ }^{[21,22]}$ The Cronbach's alpha for the total CCFNI for this study was $r=0.93$ and for the NMI it was $r=0.89$.

\subsection{Socio-demographic characteristics}

Socio-demographic characteristics obtained from families included age, gender, educational level, how long the patient was in the ICU, and relation to patient. For critical care nurses it included information related to age, gender, years of experience, and degree obtained (Bachelor or Master of Science in Nursing [BSN] or [MSN]).

\subsection{Ethical approval}

The study was conducted after approval had been received from the ethics committee of the university (NUR.LB03).

\subsection{Procedure}

The investigator approached family members who met the criteria and asked their interest in participating. They were informed about the study and their voluntary participation. If they agreed to participate, they were given the consent form to sign and the survey to complete in a private conference room. Participants were advised that they could withdraw from the survey at any time. After they agreed to participate, they signed the consent form and were given the survey to complete including the demographic data questionnaire and the CCFNI/NMI. All 92 nurses working in the four ICUs received an online survey, which included an introductory email with a link to the consent to participate and answer the survey.

Published by Sciedu Press

\subsection{Statistical analysis}

Sample size was based on a previous study ${ }^{[15]}$ which found a significant difference between the age of nurses and their scores on the CCNFI. Using the formula below, an alpha of 0.05 and a beta of 0.84 with the CCFNI scores from this latter study, a sample size of 41 per group was obtained $\mathrm{N}=$ $\left(\sigma_{1}{ }^{2}+\sigma_{2}{ }^{2}\right)\left(Z_{\alpha}+Z_{\beta}\right)^{2} /\left(\mu_{2}-\mu_{1}\right)^{2}$. All online responses and survey responses were exported into IBM SPSS version 24. Descriptive statistics were used to illustrate participants' socio-demographic characteristics. The mean scores on the five CCFNI/NMI subscales were compared using $t$-tests. Any significant differences between the individual items on the CCFNI and the NMI between family members and nurses were also reported using $t$-tests. The relationship between the socio-demographic variables, the five subscales on CCFNI, and the individual items on the CCFNI were compared using ANOVA, followed by Bonferroni analysis for more than two categories, and independent $t$-tests for variables with two categories. Age was divided into less than 40 years and above 40 years for family members, and less than 25 years and above 25 years for nurses. Years of experience for nurses was divided into three categories: six months to four years, four to eight years and more than eight years. For family members, education was divided into less than 12 years, high school, and university; and for nurses it was holding a BSN degree or an MSN degree. How long the patient was in the ICU was divided into 24 to 36 hours, 37 to 72 hours, and more than 72 hours. The level of significance was set at .05 .

\section{Results}

\subsection{Socio-demographic characteristics of critical care nurses}

The mean ages of nurses was $32.5( \pm 7.6)$, with $6.84( \pm 3.2)$ years of experience; 27 (54\%) were males; and 34 (68\%) held a BSN and $16(32 \%)$ held an MSN. For family members, the mean age was $42.5( \pm 7.43)$; $30(60 \%)$ were females; $32(64 \%)$ had a university degree. Most of the family members who participated in the study were children of patients $(48 \%)$, followed by parents $(30 \%)$, and spouses (10\%); the remaining were nieces, uncles/aunts, grandparents, or cousins. Table 1 displays the overall demographic characteristics of family members and nurses.

\subsection{What are the significant differences, if any, between how critical care nurses compared to family mem- bers perceive their needs during a family member's critical illness?}

Both families and nurses ranked 'Assurance' as the most important need (see Table 2), with the four remaining domains differing between families and nurses, albeit none reached significance. In terms of the ranking of the individual items, 
there were significant differences between the nurses and families on 17 of the 30 items on the CCFNI as shown in Table 3. Six items were related to 'Information,' three to 'Assurance,' three to 'Support,' four to 'Proximity,' and one to 'Comfort.' Nurses perceived the top three family needs to be: "to talk to the doctor every day" $(p=.02)$, "to know the prognosis" $(p=.02)$, and "to know how the patient is being treated" $(p=.04)$. Whereas families perceived their top 3 priorities to be "to know exactly what is being done to the patient" ( $p=.00)$, "to be assured that the best possible care is being given to the patient" ( $p=.01)$, and "to receive information about the patient once a day" $(p=.00)$. The reaming significant differences are noted in Table 3.

Table 1. Socio-demographic characteristics of family members and nurses

\begin{tabular}{|c|c|c|c|c|}
\hline \multirow{2}{*}{ Variables } & \multicolumn{2}{|c|}{ Family members $(\mathrm{N}=\mathbf{5 0})$} & \multicolumn{2}{|c|}{ Nurses $(\mathrm{N}=50)$} \\
\hline & $\mathbf{n}$ & $\%$ & $\mathbf{n}$ & $\%$ \\
\hline \multicolumn{5}{|l|}{ Age } \\
\hline $18-25$ & 15 & 30 & 18 & 36 \\
\hline $26-40$ & 7 & 14 & 30 & 60 \\
\hline $41-60$ & 23 & 46 & 2 & 4 \\
\hline Above 60 & 5 & 10 & 0 & 0 \\
\hline \multicolumn{5}{|l|}{ Gender } \\
\hline Female & 30 & 60 & 23 & 46 \\
\hline Male & 20 & 40 & 27 & 54 \\
\hline \multicolumn{5}{|c|}{ Length of patients stay in Critical Care Areas } \\
\hline 24 hours to 36 hours & 15 & 30 & & \\
\hline 37 hours to 72 hours & 9 & 18 & & \\
\hline More than 72 hours & 26 & 52 & & \\
\hline \multicolumn{5}{|c|}{ Relationship of the family member to the patient } \\
\hline Child & 24 & 48 & & \\
\hline Parent & 15 & 30 & & \\
\hline Spouse & 5 & 10 & & \\
\hline Nephews/nieces & 3 & 6 & & \\
\hline Aunts/uncles & 2 & 4 & & \\
\hline Grandparents & 1 & 2 & & \\
\hline \multicolumn{5}{|c|}{ Length of patients stay in Critical Care Areas } \\
\hline 24 hours to 36 hours & 15 & 30 & & \\
\hline 37 hours to 72 hours & 9 & 18 & & \\
\hline More than 72 hours & 26 & 52 & & \\
\hline \multicolumn{5}{|c|}{ Family members' level of education } \\
\hline Secondary & 3 & 6 & & \\
\hline High school & 7 & 14 & & \\
\hline Bachelor’s degree & 32 & 64 & 34 & 68 \\
\hline Master’s degree & 8 & 16 & 16 & 32 \\
\hline \multicolumn{5}{|c|}{ How many years as a nurse } \\
\hline 6 months-2 years & 10 & 20 & & \\
\hline 2.1-8 years & 24 & 48 & & \\
\hline$>8$ years & 16 & 32 & & \\
\hline
\end{tabular}

3.3 What are the significant differences, if any, between how critical care nurses and family members perceive if their needs are being met or not during a family member's critical illness?

The mean scores of the NMI are noted in Table 2. The results showed that the subscales were not significantly different between groups, although family members ranked 'Assurance' as the first met need while nurses noted that 'Proximity' was the most met need. In terms of the significant differences on the individual items on the NMI, the results showed that family members and nurses had significant differences in whether they perceived that their needs were being met or not on five items out of the 30 items (see Table 4). 
Table 2. Nurses' and families' mean scores on the five needs domains on the CCFNI and the NMI

\begin{tabular}{|c|c|c|c|c|c|c|}
\hline \multirow{2}{*}{ Domain } & \multirow{2}{*}{ Items } & \multicolumn{2}{|c|}{ Family Mean \pm SD } & \multicolumn{2}{|c|}{ Nurses Mean \pm SD } & \multirow{2}{*}{$p$} \\
\hline & & CCFNI (N = 50) & NMI & CCFNI $(N=50)$ & NMI & \\
\hline Assurance & 7 & $3.80 \pm .76$ & $3.39 \pm 0.67$ & $3.71 \pm 1.10$ & $3.17 \pm 0.70$ & .13 \\
\hline Information & 7 & $3.72 \pm .85$ & $3.26 \pm 0.83$ & $3.47 \pm .96$ & $3.29 \pm 0.73$ & .11 \\
\hline Proximity & 7 & $3.58 \pm 1.22$ & $3.21 \pm 0.78$ & $3.55 \pm .88$ & $3.12 \pm 0.71$ & .16 \\
\hline Comfort & 2 & $3.45 \pm .95$ & $3.20 \pm 0.89$ & $3.23 \pm 1.02$ & $3.08 \pm 0.72$ & .21 \\
\hline Support & 7 & $3.22 \pm .79$ & $2.90 \pm 0.96$ & $3.27 \pm .87$ & $2.82 \pm 0.72$ & .46 \\
\hline
\end{tabular}

Table 3. Results of the independent $t$-test for family members and nurses perceived regarding importance of needs

\begin{tabular}{|c|c|c|c|c|c|c|}
\hline \multirow{2}{*}{ Perceived need } & \multicolumn{2}{|c|}{ Family $\mathbf{N}=\mathbf{5 0}$} & \multicolumn{2}{|c|}{ Nurses $\mathbf{N}=50$} & \multirow{2}{*}{$t$-test } & \multirow{2}{*}{$p$} \\
\hline & Mean & SD & Mean & SD & & \\
\hline To feel accepted by the hospital staff & 3.66 & 0.59 & 3.32 & 0.82 & 2.38 & .02 \\
\hline To talk to the doctor every day & 3.84 & 0.42 & 3.92 & 0.27 & -1.12 & .02 \\
\hline To know how the patient was being treated & 3.86 & 0.40 & 3.76 & 0.48 & 1.13 & .04 \\
\hline To talk about feelings & 2.76 & 1.08 & 3.14 & 0.70 & -2.09 & .00 \\
\hline To have directions regarding what to do at the bedside & 3.48 & 0.71 & 3.26 & 0.72 & 1.54 & .97 \\
\hline To have visiting hours start on time & 3.12 & 1.00 & 3.44 & 0.88 & -1.69 & .31 \\
\hline To know why things were done for the patient & 3.84 & 0.42 & 3.64 & 0.60 & 1.93 & .00 \\
\hline To know exactly what was being done for the patient & 3.88 & 0.33 & 3.26 & 0.64 & 3.13 & .00 \\
\hline To have someone concerned with the family member's health & 3.32 & 0.82 & 3.12 & 0.87 & 1.18 & .80 \\
\hline To see the patient frequently & 3.84 & 0.47 & 3.16 & 0.56 & 1.75 & .00 \\
\hline To be told about $\mathrm{t}$ transfer plans & 3.66 & 0.63 & 3.68 & 0.59 & -0.16 & .68 \\
\hline To know about the types of staff taking care of the patient & 3.48 & 0.68 & 3.16 & 0.77 & 2.21 & .46 \\
\hline To be assured that the best possible care was being given to the patient & 3.86 & 0.40 & 3.34 & 0.49 & 1.34 & .01 \\
\hline To be called at home about changes in the p patient's condition & 3.78 & 0.55 & 3.22 & 0.89 & 3.80 & .00 \\
\hline To have friends nearby for support & 3.04 & 1.03 & 3.02 & 0.82 & 0.11 & .09 \\
\hline To help with the patient’s physical care & 3.54 & 0.58 & 2.92 & 1.01 & 3.77 & .00 \\
\hline To talk with the nurse each day & 3.36 & 0.88 & 3.58 & 0.67 & -1.41 & .07 \\
\hline To talk about the possibility of the patient's death & 3.12 & 1.15 & 3.50 & 0.74 & -1.96 & .00 \\
\hline To have a telephone in the waiting room & 3.24 & 1.02 & 3.14 & 0.97 & 0.50 & .41 \\
\hline To know the prognosis & 3.70 & 0.61 & 3.82 & 0.39 & -1.17 & .02 \\
\hline To have explanations of the environment before going in & 3.42 & 0.84 & 3.42 & 0.70 & 0.00 & .57 \\
\hline To feel there was hope & 3.84 & 0.42 & 3.64 & 0.60 & 1.93 & .00 \\
\hline To have a specific person to call at the hospital when not there & 3.58 & 0.76 & 3.36 & 0.83 & 1.39 & .26 \\
\hline To have visiting hours or restrictions changed for special conditions & 3.42 & 0.76 & 3.60 & 0.57 & -1.34 & -.03 \\
\hline To receive information about the patient once a day & 3.86 & 0.40 & 3.28 & 0.51 & 1.95 & .00 \\
\hline To have questions answered honestly & 3.84 & 0.37 & 3.36 & 0.56 & 1.90 & .00 \\
\hline To feel that hospital personnel cared about the patient & 3.82 & 0.44 & 3.74 & 0.48 & 0.66 & .24 \\
\hline To be told about other people who could help with problems & 3.42 & 0.86 & 3.40 & 0.76 & 0.12 & .78 \\
\hline To know specific facts about the patient's condition & 3.78 & 0.46 & 3.66 & 0.59 & 1.13 & .03 \\
\hline To have explanations given in terms that are understandable & 3.74 & 0.56 & 3.70 & 0.61 & 0.34 & .61 \\
\hline
\end{tabular}


Table 4. Results of independent $t$-test between Nurses and Family Members on the NMI

\begin{tabular}{|c|c|c|c|c|c|c|}
\hline Unmet Need & $\begin{array}{l}\text { Family Mean } \\
\mathrm{N}=50\end{array}$ & SD & $\begin{array}{l}\text { Nurses Mean } \\
\mathrm{N}=50\end{array}$ & SD & $t$ & $p$ \\
\hline To feel accepted by the hospital staff & 3.54 & 0.58 & 3.20 & 0.67 & 2.72 & .87 \\
\hline To talk to the doctor every day & 3.22 & 0.82 & 2.96 & 0.75 & 1.65 & .23 \\
\hline To know how the patient was being treated & 3.52 & 0.61 & 3.34 & 0.63 & 1.45 & .96 \\
\hline To talk about feelings & 2.68 & 0.97 & 3.13 & 0.72 & -0.23 & .05 \\
\hline To have directions regarding what to do at the bedside & 3.14 & 0.90 & 3.16 & 0.67 & 0.92 & 1.01 \\
\hline To have visiting hours start on time & 3.34 & 0.75 & 3.22 & 0.68 & 0.84 & .34 \\
\hline To know why things were done for the patient & 3.48 & 0.61 & 3.34 & 0.59 & 1.16 & .50 \\
\hline To know exactly what was being done for the patient & 3.40 & 0.64 & 3.20 & 0.70 & 1.49 & 1.00 \\
\hline To have someone concerned with the family member's health & 2.92 & 0.90 & 2.66 & 0.77 & 1.55 & .89 \\
\hline To see the patient frequently & 3.64 & 0.60 & 3.02 & 0.74 & 4.60 & .59 \\
\hline To be told about transfer plans & 3.16 & 0.91 & 3.30 & 0.65 & -0.89 & .12 \\
\hline To know about the types of staff taking care of the patient & 3.12 & 0.77 & 3.14 & 0.67 & -0.14 & 62 \\
\hline To be assured that the best possible care was being given to the patient & 3.52 & 0.54 & 3.38 & 0.64 & 1.18 & .23 \\
\hline To be called at home about changes in the patient's condition & 2.96 & 1.09 & 2.46 & 0.86 & 2.55 & .28 \\
\hline To have friends nearby for support & 3.10 & 0.86 & 2.46 & 0.68 & 4.13 & .56 \\
\hline To help with the patient's physical care & 3.16 & 0.87 & 2.68 & 0.89 & 2.73 & .39 \\
\hline To talk with the nurse each day & 3.32 & 0.79 & 3.54 & 0.65 & -1.52 & .12 \\
\hline To talk about the possibility of the patient's death & 2.36 & 1.18 & 2.68 & 0.79 & -1.09 & .00 \\
\hline To have a telephone in the waiting room & 2.86 & 1.21 & 3.38 & 0.81 & -2.53 & .00 \\
\hline To know the prognosis & 3.24 & 0.82 & 3.20 & 0.70 & 0.26 & .49 \\
\hline To have explanations of the environment before going in & 2.92 & 0.92 & 3.08 & 0.72 & -0.96 & .25 \\
\hline To feel there was hope & 3.38 & 0.67 & 2.80 & 0.73 & 4.15 & .61 \\
\hline To have a specific person to call at the hospital when not there & 2.48 & 1.14 & 2.90 & 0.81 & -1.61 & .00 \\
\hline To have visiting hours or restrictions changed for special conditions & 2.86 & 1.09 & 3.45 & 0.80 & -0.31 & .01 \\
\hline To receive information about the patient once a day & 3.54 & 0.61 & 3.40 & 0.64 & 1.12 & .64 \\
\hline To have questions answered honestly & 3.38 & 0.67 & 3.22 & 0.74 & 1.14 & .67 \\
\hline To feel that hospital personnel cared about the patient & 3.46 & 0.61 & 3.30 & 0.71 & 1.21 & .35 \\
\hline To be told about other people who could help with problems & 2.98 & 1.04 & 2.90 & 0.74 & 0.44 & .06 \\
\hline To know specific facts about the patient's condition & 3.38 & 0.67 & 3.16 & 0.68 & 1.63 & .66 \\
\hline To have explanations given in terms that are understandable & 3.34 & 0.77 & 3.16 & 0.77 & 1.17 & .75 \\
\hline
\end{tabular}

3.4 What are the significant relationships, if any, between the demographic characteristics of nurses and families and their perceptions of needs during a family member's critical illness?

There were no significant differences in any of the five domains and socio-demographic characteristics of nurses, however there were significant differences on five items on the CCFNI. Nurses with more than eight years of experience had significantly higher scores on two items compared to nurses with fewer years of experience: one related to 'Information', "to know how the patient is being treated" $(3.42 \pm 0.22 \mathrm{vs}$ $3.04 \pm 0.35, \mathrm{~F}=2.45, p=.03)$; and one related to 'Comfort', "to feel accepted by staff" ( $3.28 \pm 0.43$ vs $3.18 \pm 0.32, F=$ $3.06, p=.01)$. Nurses older than 40 years perceived the need to know "exactly what is being done to the patient" ( $3.09 \pm$ 0.34 vs. $2.87 \pm 0.44, \mathrm{~F}=3.04, p=.004)$ and to "to be called at home about changes in the patient's condition" (3.74 \pm 0.09 vs. $3.05 \pm 0.45, \mathrm{~F}=2.56, p=.015$ ) as significantly more important than younger nurses. Nurses with a BSN degree scored higher than nurses with an MSN on four items, three related to 'Information' and one to 'Assurance'. Nurses with a BSN degree rated the need "to know why things are done for the patient" $(3.71 \pm 0.19$ vs. $3.50 \pm 0.46, \mathrm{~F}=$ $2.45, p=.03)$, "to know what is exactly is being done to the patient" ( $3.42 \pm 0.22$ vs. $3.04 \pm 0.3, \mathrm{~F}=3.12, p=.008)$, "to talk to the doctor every day" ( $3.97 \pm 0.23$ vs. $3.59 \pm 0.34, \mathrm{~F}$ $=2.45, p=.03$ ), and "to have questions answered honestly" ( $3.71 \pm 0.28$ vs $3.56 \pm 0.46, \mathrm{~F}=3.22, p=0.03$ ) higher than 
nurses with an MSN degree.

Male nurses scored significantly higher than females on nine perceived needs (see Table 5). From the nine family needs, three were related to the need for information category: "to know how the patient was being treated" $(p=.02)$, "to know why things were done for the patient" $(p=.04)$, and "to know exactly what was being done for the patient" $(p=.01)$. Male nurses scored higher means on two statements related to Proximity: "to talk with the nurse every day" ( $p=.04)$ and "to be told about transfer plans" ( $p=.03)$. In addition, male nurses also scored higher on four needs which were related to Assurance: "to be assured that the best possible care was being given to the patient" ( $p=.04)$, "to know the prognosis" $(p=.02)$, "to know specific facts about the patient's condition" $(p=.01)$, and "to have questions answered honestly" $(p=.01)$.

Table 5. Differences of perceived needs on the CCNFI according to gender of nurses

\begin{tabular}{|c|c|c|c|c|c|}
\hline \multirow{3}{*}{ Family Need } & \multicolumn{5}{|c|}{ NURSES } \\
\hline & \multicolumn{2}{|c|}{ Female } & \multicolumn{2}{|c|}{ Male } & \multirow{2}{*}{$p$} \\
\hline & $\mathbf{N}$ & Mean \pm SD & $\mathbf{N}$ & Mean \pm SD & \\
\hline To know how the patient was being treated & 23 & $3.52 \pm 0.23$ & 27 & $3.96 \pm 0.43$ & .01 \\
\hline To be told about transfer plans & 23 & $3.43 \pm 0.67$ & 27 & $3.89 \pm 0.67$ & .00 \\
\hline To know the prognosis & 23 & $3.53 \pm 0.45$ & 27 & $3.93 \pm 0.93$ & .00 \\
\hline To know why things were done for the patient & 23 & $3.39 \pm 0.46$ & 27 & $3.85 \pm 0.44$ & .00 \\
\hline To know specific facts about the patient's condition & 23 & $3.48 \pm 0.76$ & 27 & $3.81 \pm 0.38$ & .00 \\
\hline To have questions answered honestly & 23 & $3.48 \pm 0.24$ & 27 & $3.81 \pm 0.54$ & .00 \\
\hline To talk with the nurse each day & 23 & $3.30 \pm 1.01$ & 27 & $3.81 \pm 0.65$ & .00 \\
\hline To be assured that the best possible care was being given to the patient & 23 & $3.64 \pm 0.89$ & 27 & $3.85 \pm 0.78$ & .01 \\
\hline To know exactly what was being done for the patient & 23 & $3.35 \pm 0.67$ & 27 & $3.74 \pm 0.54$ & .02 \\
\hline
\end{tabular}

For families, family members older than 40 years scored higher than younger family members on three items related to 'Assurance' and one related to 'Information'. Older family members perceived "the need to be assured that the best possible care is being given to the patient" (3.92 \pm 0.33 vs. 2.98 $\pm 0.7, t=2.59, p=.04)$, "to know the prognosis" (3.67 \pm 0.21 . vs. 3.01, $t=2.12, p=.03)$, and "to have explanations that are understandable" $(3.29 \pm 0.17$ vs. $2.51 \pm 0.9, t=$ $3.15, p=.02)$ as well as "to help with physical care" $(3.05$ \pm 0.08 vs. $2.50 \pm 0.6, t=3.13, p=.02$ ) significantly more important than younger family members. In terms of gender, women had significantly higher scores than men on five perceived needs, three related to Proximity: "to be told about transfer plans" $(3.22 \pm 0.12$. vs. $2.67 \pm 1.1, t=3.13, p=$ $.02)$, "to see the patient frequently" $(3.05 \pm 0.08$. vs. 2.50 $\pm 1.2, t=3.13, p=.02$ ), and "to be called at home about changes in the patient's condition" $(3.93 \pm 0.12$ vs $3.05 \pm$ $1.1, t=2.97, p=.02)$. One item was related to 'Information,' "to help with the patients physical care" (3.67 \pm 0.09 vs. 3.21 $\pm 0.9, t=3.05, p=0.02)$. One item was related to 'Support,' "to talk about feelings" $(2.93 \pm 0.13$ vs. $2.50 \pm 0.8, t=2.33$, $p=.04)$. However, male family members scored significantly higher than females on two perceived needs: one related to 'Information', "to know exactly what was being done for the patient" $(3.95 \pm 1.13$ vs. $3.78 \pm 0.7, t=2.56, p=.02)$, and one related to 'Support', to "to talk about the possibility of the patients death" $(3.40 \pm 1.08$ vs. $2.93 \pm 1.02, t=3.18, p$ $=.04)$.

Family members who were more educated (a university degree) had significantly higher scores on four out of the 30 items on the CCFNI. Three items were related to 'Knowledge': "to know how the patient is being treated" $(2.87 \pm$ 1.01 vs. $2.04 \pm 0.07, \mathrm{~F}=2.34, p=.04)$, "to know what why things are being done for the patient" $(3.12 \pm 0.05$ vs. 2.08 $\pm 1.13, \mathrm{~F}=2.05, p=.04)$, and "to know exactly what is being for the patient" (3.06 \pm 1.01 vs. $2.65 \pm 0.07, \mathrm{~F}=3.01$, $p=0.04)$. One item was related to 'Prognosis,' to "know the prognosis" $(2.89 \pm 0.06$ vs. $2.03 \pm 0.06, \mathrm{~F}=5.40, p=$ $.00)$. Family members with a less than a high school education had higher scores compared to family members with high school or university on three items, two items related to 'Proximity' and one to 'Assurance': “to talk to the nurse every day" ( $3.08 \pm 0.05$ vs. $2.66 \pm 1.02, \mathrm{~F}=5.40, p=.00)$, "to receive information about patient once a day" (2.76 \pm 1.01 vs. $2.05 \pm 1.02, \mathrm{~F}=5.40, p=.04)$, and "to feel hope" $(3.01 \pm 1.02$ vs. $2.23 \pm 0.09, \mathrm{~F}=3.89, p=.01)$. Kinship to the patient and days in the ICU had no relationship to their perceived needs. 


\section{Discussion}

This is the first study in Lebanon to assess the needs of families of patients in the ICU, and to also compare family and nurse perceptions of met and unmet needs with the relationship between socio-demographic variables. The demographic characteristics of nurses and families are similar to what is reported in previous studies from this institution. ${ }^{[3,23]}$

Perceived needs: We found that both the families and nurses ranked 'Assurane' as most significant while 'Comfort' and 'Proximity' ranked lowest, which is in accordance with several earlier studies in Western, Asian, and Middle Eastern countries where 'Assurance' and 'Information' ranked higher than needs for 'Support' and 'Comfort' ${ }^{[7,13,20,24-27]}$ It is expected than when a loved one is in critical condition, the primary concern of family members is the wellbeing of the patient and not their own needs for support or comfort. Despite the similarities in the ranking of the family needs between the nurses and the family members on the five domains, there were significant differences on 17 out of the 30 items. Five individual needs were associated with 'Information', five were for 'Assurance,' four were related to 'Proximity', two for 'Support', and one for 'Comfort'. For the nurses, they perceived that the top three family needs were: "to talk to the doctor every day" (Information), "to know the prognosis" (Assurance), and "to know how the patient is being treated" (Information); whereas, families perceived their top three priorities to be: "to know how the patient was being treated" (Information), "to be assured that the best possible care is being given to the patient" (Assurance), and "to receive information about the patient once a day" (Proximity). These findings indicate that while both families and nurses value the need for information and assurance they had different opinions on what kind of information or assurance is important for them.

In support of our results, several studies report inconsistencies in the individual items across cultures. For example, in a study in Greece ${ }^{[7]}$ and in a study in Spain ${ }^{[2]}$ both noted that families identified "to have questions answered honestly" as the most important need on the CCFNI. A study in the United States found that "to be assured that the best care possible is being given to the patient" was rated as the first need followed by "to know exactly what is being done for the patient" and "to have questions answered honestly". ${ }^{[6]}$

In terms of nurses, a study in Iran found that nurses ranked the need "to be assured that the best care possible is being given to the patients" as the highest priority, whereas in this study the highest score given by nurses was "to talk to the doctor every day" followed by "to know the prognosis". ${ }^{\text {[9] }}$ The fact that nurses ranked "to talk the doctor every day" as the number one perceived need for relatives is rather surprising and unlike most published studies. ${ }^{[24,28]}$ It is plausible that in this culture the physician is still regarded as the most important healthcare provider by nurses. These discrepancies could be explained by the fact that different institutions and cultures have different values and needs that should be taken into consideration when providing care to patients.

Met and unmet needs: There were no significant differences in the ranking of the five domains of the met and unmet needs. However while families regarded 'Assurance' as the most met need, nurses perceived 'Proximity' as the most met need. 'Support' and 'Comfort' received the lowest scores by both, which is in accordance with earlier studies. ${ }^{[5,20,26]}$ There were significant differences between families and nurses on only five out of 30 items, indicating that most families and nurses had similar opinions on their met and unmet needs. Families' unmet needs were related to 'Support', "talking about feelings and about the possibility of the patient's death", 'Information', "having a specific person to call at the hospital when not there", 'Comfort", having a telephone in the waiting room", and 'Proximity', "having liberal visiting hours". These findings indicate that while families do not perceive 'Comfort' or 'Support' as their most important needs, they felt that their needs for 'Comfort', 'Support', and 'Proximity' were not met. In contrast they felt that their need for 'Information' and 'Assurance' were mostly met. Consistent with our results, other have noted that nurses felt that talking about the possibility of the patient's death and talking about feelings were met more than families did. ${ }^{[16]}$ Talking about feelings and a patient's possible death may not be easy concepts for nurses to handle especially when they are overworked and the patient's wellbeing and saving his/her life is their priority. Furthermore, at this institution, talking about a patient's death is considered a physician rather than not a nurse responsibility.

Although these ICUs have flexible visiting hours, families are not authorized to see their relative at all times or to be directly involved in their care, thus they felt that those hours could be more flexible. It is well documented in the literature that family and friend visits can improve patients' wellbeing, diminish their anxiety, and maintain their physiological indices within normal limits. ${ }^{[29]}$

\subsection{Differences of perceived needs according to nurses' socio-demographic characteristics}

Registered nurses with a BSN scored higher than those with an MSN on four items: three related to 'Information, and one to 'Assurance'. Although no previous studies compared nurses with a BSN to those with an MSN, some previous studies report a relationship between education and the nurses' 
perception of family needs. ${ }^{[5,24]}$ This finding may indicate that nurses with an MSN may not be proving direct patient care and are thus less attuned to the family's needs. Male nurses scored higher on nine items related to 'Information', 'Proximity', and 'Assurance'. This is an interesting finding not accounted for in previous studies. Is it possible that male nurses are more sensitive to the needs of families? It is worth noting than $57 \%$ of the nurse participants were male, which is uncommon in previous studies. Nurses with more than eight years of experience had significantly higher scores on two items than nurses with fewer years of experience, one related to 'Information' and one related to 'Comfort'. Older nurses also scored significantly higher than younger nurses on one item related to 'Information' and one item on 'Proximity'. These findings could be explained by the fact that older nurses, with more years of experience, may be more attuned to the needs of their patients for 'Information', 'Proximity', and 'Comfort'. Earlier studies provide inconstant answers in terms of years of experience or age and the nurses' ability to perceive family needs. For example, Verhaeghe et al. found that more years of experience result in less ability to assess family needs. ${ }^{[30]}$ Similarly, Davidson noted that older nurses are less able to predict the needs of families. ${ }^{[31]}$ However, Takman and Severinsson reported that nurses with more years of experience were more sensitive to family needs. ${ }^{[32]}$

\subsection{Differences of perceived needs according to families' socio-demographic characteristics}

Family members older than 40 years scored higher than younger family members on three items two related to 'Assurance' and one related to 'Information', which is supported by an earlier study. ${ }^{[27]}$ In contrast, two studies indicate that younger visitors of patients in the ICU regarded their needs as more important than older visitors. ${ }^{[33,34]}$ The discrepancy in results could be explained by the fact the participants in this study were younger than most participants in earlier studies. In terms of gender, women had significantly higher scores than men on five perceived needs: three related to 'Proximity', one related to 'Information', and one related to 'Support'. However, male family members scored significantly higher than females on two perceived needs: one related to 'Information' and one related to 'Support'. While an earlier study found that education, gender, and age did not influence how families perceived their needs, ${ }^{[35]}$ another study reported a significant influence of age and education on perceived needs. ${ }^{[3]}$ While most studies find that with exception of the need for information, women report higher scores on needs especially in terms of support. ${ }^{[29,30,34]}$ Family members who were more educated (a university degree) had significantly higher scores on four out of the 30 items on the CCFNI: three items were related to 'Information' and one item was related to 'Assurance'. Family members with less than a high school education had higher scores compared to family members with high school or university on three items: two items related to 'Proximity' and one to 'Assurance'. A few studies have reported that while more educated people have fewer needs than the less educated people, the less educated have more need for support. ${ }^{[29,30,34]}$ Our findings can be explained by the fact that more educated families have more need to understand facts about their relatives in the ICU while less educated family members need to be assured and to be close their loved ones.

\subsection{Limitations}

The strength of this study is that it is among the few that assessed both perception of needs as well as whether those needs were met or not by both family members and nurses as well as the relationships between socio-demographic variables and perceptions. Nevertheless, there are a few limitations worth noting. A convenience sample from one institution was used which limits generalizability to other hospitals and cultures. We also did not assess the patients' severity of illness which may have affected the results.

\subsection{Implications for practice}

The main conclusion derived from the results is that families of critically ill patients could benefit from more support from nurses and more open communication. Visitation hours, though unrestricted in at this institution, could benefit from allowing families to be closer to their loved ones, and share in their care. The importance of socio-demographic variables on how nurses and family members regard their needs should also be taken into consideration when providing care to patients in critical care units.

\section{Conflicts of InTEREST Disclosure}

The authors declare that there is no conflict of interest.

\section{REFERENCES}

[1] Hughes F, Robbins I, Bryan K. An analysis of information available to relatives in intensive care. Intens Crit Care Nur. 2004; 20(4): 200-5.
PMid:15288873 https://doi.org/10.1016/j.iccn.2004.04 .005

[2] Velasco Bueno JM, Alonso-Ovies A, Heras La Calle G, et al. Equipo 
de investigación del Proyecto HUCI (Humanizando los Cuidados Intensivos). Main information requests of family members of patients in intensive care units. Med Intensiva. 2018; 42(6): 337-45. PMid:29108720 https://doi.org/10.1016/j .medin.2017.0 9.007

[3] Hajj M, Gulgulian T, Haydar L, et al. The satisfaction of families in the care of their loved ones in CCUs in Lebanon. Nurs Crit Care. 2017; 22(4): 203-11. PMid:26256561 https://doi.org/10.111 $1 /$ nicc. 12195

[4] Stricker KH, Kimberger O, Schmidlin K, et al. Family satisfaction in the intensive care unit: What makes the difference? Intensive Care Med. 2009; 35(12): 2051-2059. PMid:19730813 https : //doi.org/10.1007/s00134-009-1611-4

[5] Abdel-Aziz AL, Ahmed SES, Younis GAE-H. Family Needs of Critically Ill Patients Admitted to the Intensive Care Unit, Comparison of Nurses and Family Perception. Am J Nurs Sci. 2017 Aug; 6(4): 333. https://doi .org/10.11648/j . ajns . 20170604.18

[6] Hinkle JL, Fitzpatrick E. Needs of American relatives of intensive care patients: Perceptions of relatives, physicians and nurses. Intens Crit Care Nur. 2011; 27(4): 218-225. PMid:21680185 https : //doi.org/10.1016/j.iccn.2011.04.003

[7] Chatzaki M, Klimathianaki M, Anastasaki M, et al. Defining the needs of ICU patient families in a suburban/rural Greek population: A prospective cohort study. J Clin Nurs. 2012; 21(13-14): 1831-1839. PMid:22509724 https://doi .org/10.1111/j.1365-2702.20 $11.04022 . x$

[8] Omari FH, AbuAlRub R, Ayasreh IR. Perceptions of patients and nurses towards nurse caring behaviors in coronary care units in Jordan. J Clin Nurs. 2013; 22(21-22): 3183-3191. PMid:24118521 https://doi.org/10.1111/jocn. 12458

[9] Shorofi SA, Jannati Y, Moghaddam HR, et al. Psychosocial needs of families of intensive care patients: Perceptions of nurses and families. Niger Med J. 2016; 57(1): 10-18. PMid:27185973 https : //doi.org/10.4103/0300-1652.180557

[10] Myhren H, Ekeberg Ø, Stokland O. Satisfaction with communication in ICU patients and relatives: Comparisons with medical staffs' expectations and the relationship with psychological distress. Patient Educ Couns. 2011; 85(2): 237-244. PMid:21167672 https://doi.org/10.1016/j.pec.2010.11.005

[11] Kandasamy S, Vijayakumar N, Natarajan RK, et al. Psychosocial Needs of Patient's Relatives and Health Care Providers in a Pediatric Critical Care Unit. Indian J Pediatr. 2017; 84(8): 601-6. PMid:28299540 https://doi.org/10.1007/s12098-017-232 4-2

[12] Damghi N, Khoudri I, Oualili L, et al. Measuring the satisfaction of intensive care unit patient families in Morocco: A regression tree analysis. Crit Care Med. 2008; 36(7): 2084-2091. PMid:18552683 https://doi.org/10.1097/CCM.0b013e31817c104e

[13] Al-Mutair AS, Plummer V, Obrien A, et al. Family needs and involvement in the intensive care unit: A literature review. J Clin Nurs. 2013; 22(13-14): 1805-17. PMid:23534510 https://doi .org/10 $.1111 /$ jocn. 12065

[14] Khalaila R. Meeting the needs of patients' families in intensive care units. Nurs Stand. 2014; 28(43): 37.

[15] Khatri Chhetri I, Thulung B. Perception of Nurses on Needs of Family Members of Patient Admitted to Critical Care Units of Teaching Hospital, Chitwan Nepal: A Cross-Sectional Institutional Based Study. Nurs Res Pract. 2018; 2018: 1-7. PMid:30046491 https://doi.org/10.1155/2018/1369164

[16] Maxwell KE, Stuenkel D, Saylor C. Needs of family members of critically ill patients: A comparison of nurse and family percep- tions. Heart Lung. 2007; 36(5): 367-376. PMid:17845883 https: //doi.org/10.1016/j.hrtling. 2007.02.005

[17] Davidson JE, Powers K, Hedayat KM, et al. Clinical practice guidelines for support of the family in the patient-centered intensive care unit: American College of Critical Care Medicine Task Force 2004-2005. Crit Care Med. 2006; 35(2): 605-22. PMid:17205007 https://doi.org/10.1097/01.CCM.0000254067.14607.EB

[18] Molter N. Needs of relatives of critically ill patients: A descriptive study. Heart Lung. 1979; 8(2): 332-9.

[19] Norris LO, Grove SK. Investigation of selected psychosocial needs of family members of critically ill adult patients. Heart Lung. 1986; 15(2): 194-99.

[20] Omari FH. Perceived and Unmet Needs of Adult Jordanian Family Members of Patients in ICUs. J Nurs Scholarsh. 2009; 41(1): 28-34 PMid:19335675 https : //doi.org/10.1111/j.1547-5069.20 09.01248.x

[21] Leske JS. Internal psychometric properties of the critical care family needs inventory. Heart Lung. 1991; 20(3): 236-244.

[22] Macey BA, Bouman CC. An evaluation of validity, reliability, and readability of the Critical Care Family Needs Inventory. Heart Lung. 1991; 20(4): 398-403.

[23] Kouatly IA, Hassan MM, Yazbik-Doumit N, et al. Psychometric Testing of a Comprehensive Patient Satisfaction Survey in Arabic. J Nurs Meas. 2015; 23(2): 204-23. PMid:26284836 https: //doi.org/10.1891/1061-3749.23.2.204

[24] Gundo R, Bodole FF, Lengu E, et al. Comparison of Nurses' and Families' Perception of Family Needs in Critical Care Unit at Referral Hospitals in Malawi. Open J Nurs. 2014; 04(04): 312-20. https://doi.org/10.4236/ojn.2014.44036

[25] Al-Hassan, Hweidi IM. The perceived needs of Jordanian families of hospitalized, critically ill patients. International Journal of Nursing Practice. 2004; 10: 64-71. PMid:15056344 https: //doi.org/10.1111/j.1440-172X.2003.00460.x

[26] Meneguin S, Souza Matos TD, Miot HA, et al. Association between comfort and needs of ICU patients' family members: A crosssectional study. J Clin Nurs. 2018; 28(3-4): 538-44. PMid:30091154 https://doi.org/10.1111/jocn. 14644

[27] Noor Siah AA, Ho SE, Jafaar MZ, et al. Information needs of family members of critically ill patients in intensive care unit of a tertiary hospital. Clin Ter. 2012; 163(1): 63-67.

[28] Bijttebier P, Vanoost S, Delva D, et al. Needs of relatives of critical care patients: Perceptions of relatives, physicians and nurses. Intens Care Med. 2001; 27(1): 160-65. https://doi.org/10.1007/s0 01340000750

[29] Papastavrou E, Efstathiou G, Tsangari H, et al. Patients' and nurses' perceptions of respect and human presence through caring behaviours: A comparative study. Nurs Ethics. 2012; 19(3): 369-79. PMid:22581506 https://doi .org/10.1177/09697330114360 27

[30] Verhaeghe S, Defloor T, Zuuren FV, et al. The needs and experiences of family members of adult patients in an intensive care unit: A review of the literature. J Clin Nurs. 2005; 14(4): 501-9. PMid:15807758 https://doi.org/10.1111/j.1365-2702.2004.01081.x

[31] Davidson JE. Family-Centered Care: Meeting the Needs of Patients' Families and Helping Families Adapt to Critical Illness. Crit Care Nurse. 2009; 29(1): 28-34. PMid:19487778 https ://doi .org/10 $.4037 / \mathrm{ccn} 2009611$

[32] Takman C, Severinsson E. Comparing Norwegian nurses' and physicians' perceptions of the needs of significant others in Intensive Care Units. J Clin Nurs. 2005; 14(5): 621-631. PMid:15840077 https://doi.org/10.1111/j.1365-2702.2004.01038.x 
[33] Friðriksdóttir N, Sævarsdóttir P, Halfdánardóttir Sí, et al. Family members of cancer patients: Needs, quality of life and symptoms of anxiety and depression. Acta Oncol. 2011; 50(2): 25228. PMid:21231786 https://doi.org/10.3109/0284186X . 201 0.529821

[34] Høghaug G, Fagermoen MS, Lerdal A. The visitor's regard of their need for support, comfort, information proximity and assurance in the intensive care unit. Intens Crit Care Nur. 2012; 28(5): 263-8.

PMid:22209554 https://doi.org/10.1016/j.iccn.2011.11 .009

[35] Gundo R. Comparison of Nurses' and Families' Perception of Family Needs in Intensive Care Unit at a Tertiary Public Sector Hospital 2010. Available from: https://core.ac.uk/download/pdf/39 667671.pdf 